Somnologie $2019 \cdot 23: 147-156$

https://doi.org/10.1007/s11818-019-00215-x

Received: 1 May 2019

Accepted: 22 July 2019

Published online: 20 August 2019

(c) The Author(s) 2019

\author{
Christine Blume ${ }^{1,2,3} \cdot$ Corrado Garbazza $^{1,2} \cdot$ Manuel Spitschan ${ }^{1,2,4}$ \\ 'Centre for Chronobiology, Psychiatric Hospital of the University of Basel (UPK), Basel, Switzerland \\ ${ }^{2}$ Transfaculty Research Platform Molecular and Cognitive Neurosciences (MCN), University of Basel, Basel, \\ Switzerland \\ ${ }^{3}$ Centre for Cognitive Neuroscience, University of Salzburg, Salzburg, Austria \\ ${ }^{4}$ Department of Experimental Psychology, University of Oxford, Oxford, UK
}

\title{
Effects of light on human circadian rhythms, sleep and mood
}

\section{Anatomical architecture of the circadian system}

The central master-clock in mammalian species, including humans, is the suprachiasmatic nuclei $(\mathrm{SCN})$, a paired structure in the hypothalamus with a volume just about $0.25 \mathrm{~mm}^{3}$ per nucleus (e.g. $[45,57,84])$. Within the mammalian $\mathrm{SCN}$, a molecular oscillator keeps the clock oscillating at its normal pace. The basis of this oscillator is two interconnected molecular feedback loops of clock gene expression, a detailed description of which is beyond the scope of this review though (see [12] for a detailed explanation).

Successful interaction between body and environment however needs more than just a central clock; it also requires input pathways relaying information about the environment and the body to the SCN to achieve adequate entrainment as well as output pathways communicating timing information to the body to synchronise bodily processes with the circadian phase (• Fig. 1).

The most important zeitgeber (from German, something that "gives time") reaching the $\mathrm{SCN}$ is ambient light in the environment. In addition to processing visual stimuli in the environment, allowing us to see, the retina carries this photic information via the retinohypothalamic tract (RHT) to the SCN. The

All authors contributed equally to the manuscript.
SCN also receive non-photic information from within the body. Here, the involved pathways comprise the geniculohypothalamic tract (GHT), which communicates both non-photic and photic information (via the intergeniculate leaflet; IGL), and the raphe-hypothalamic tract (rapheHT). Additionally, SCN activity is also modulated by non-photic information via neurotransmitters and hormones such as serotonin [54] and melatonin [23], and from peripheral clocks in other tissues (see [55] for an overview).

SCN neurons adjust their circadian phase (of neural activity) according to the input of ambient light levels and its spectral composition and communicate this information via humoral and autonomic nervous system signals to the rest of the body. These output pathways are also reciprocal and thus feed information back to the SCN: The SCN-serotonin-producing raphe nuclei(RN)-SCN loop as well as the SCN-melatonin-producing pineal gland-SCN loop (• Fig. 1). More specifically, the RN can alter vigilance levels in accordance with circadian phase via serotonergic wakefulness-promoting projections to the hypothalamus and the cortex $[30,56]$.

The SCN also projects to the pineal gland, where the sleep-facilitating hormone melatonin is produced during the biological night, thereby modulating the diurnal variations between wakefulness and sleep [23]. In addition to the pathway between retina and SCN, there is recent evidence from animal studies show-

\begin{tabular}{|c|c|}
\hline \multicolumn{2}{|c|}{ Abbreviations } \\
\hline$A D H D$ & $\begin{array}{l}\text { Attention deficit hyperactivity } \\
\text { disorder }\end{array}$ \\
\hline$B L T$ & Bright light therapy \\
\hline$C C T$ & Correlated colour temperature \\
\hline CIE & $\begin{array}{l}\text { Commission Internationale de } \\
\text { l'Eclairage }\end{array}$ \\
\hline CRSWD & $\begin{array}{l}\text { Circadian rhythm sleep-wake } \\
\text { disorders }\end{array}$ \\
\hline DLMO & Dim-light melatonin onset \\
\hline EEG & Electroencephalogram \\
\hline GHT & Geniculohypothalamic tract \\
\hline IGL & Intergeniculate leaflet \\
\hline ipRGC & $\begin{array}{l}\text { Intrinsically photosensitive retinal } \\
\text { ganglion cell }\end{array}$ \\
\hline LED & Light-emitting diode \\
\hline$P R C$ & Phase response curve \\
\hline$R G C$ & Retinal ganglion cell \\
\hline RHT & Retinohypothalamic tract \\
\hline$R N$ & Raphe nuclei \\
\hline$S A D$ & Seasonal affective disorder \\
\hline SCN & Suprachiasmatic nuclei \\
\hline SSRI & $\begin{array}{l}\text { Selective serotonin reuptake } \\
\text { inhibitor }\end{array}$ \\
\hline SWA & Slow wave activity \\
\hline UV & Ultraviolet \\
\hline
\end{tabular}




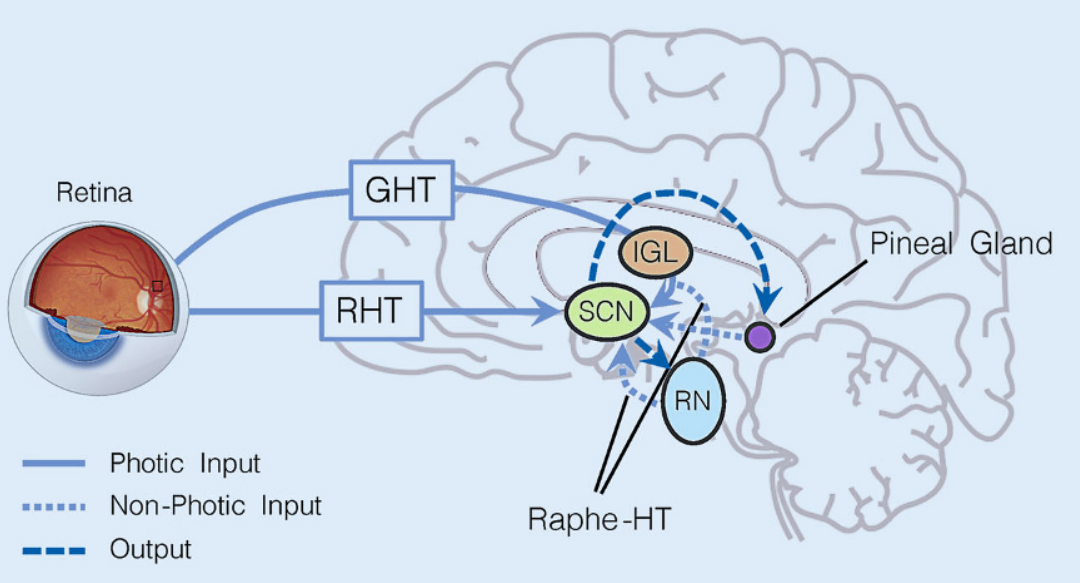

Fig. $1 \Delta$ Input and output pathways to/from the suprachiasmatic nuclei (SCN). The photic input pathways that relay information about the intensity and spectral composition of ambient light are the retinohypothalamic tract $(R H T)$ and the geniculohypothalamic tract $(G H T)$, which connects retina and $S C N$ via the intergeniculate leaflet $(I G L)$ in the thalamus. Additionally, the $S C N$ also receive non-photic information from the raphe nuclei $(R N)$ via the raphe-hypothalamic tract (raphe-HT) and from the pineal gland. The main output is from the $S C N$ to the serotonergic raphe nuclei $(R N$, receive information about the phase of the circadian clock and regulate vigilance state of the body) and the pineal gland, where melatonin is produced. Input and output pathways form reciprocal loops
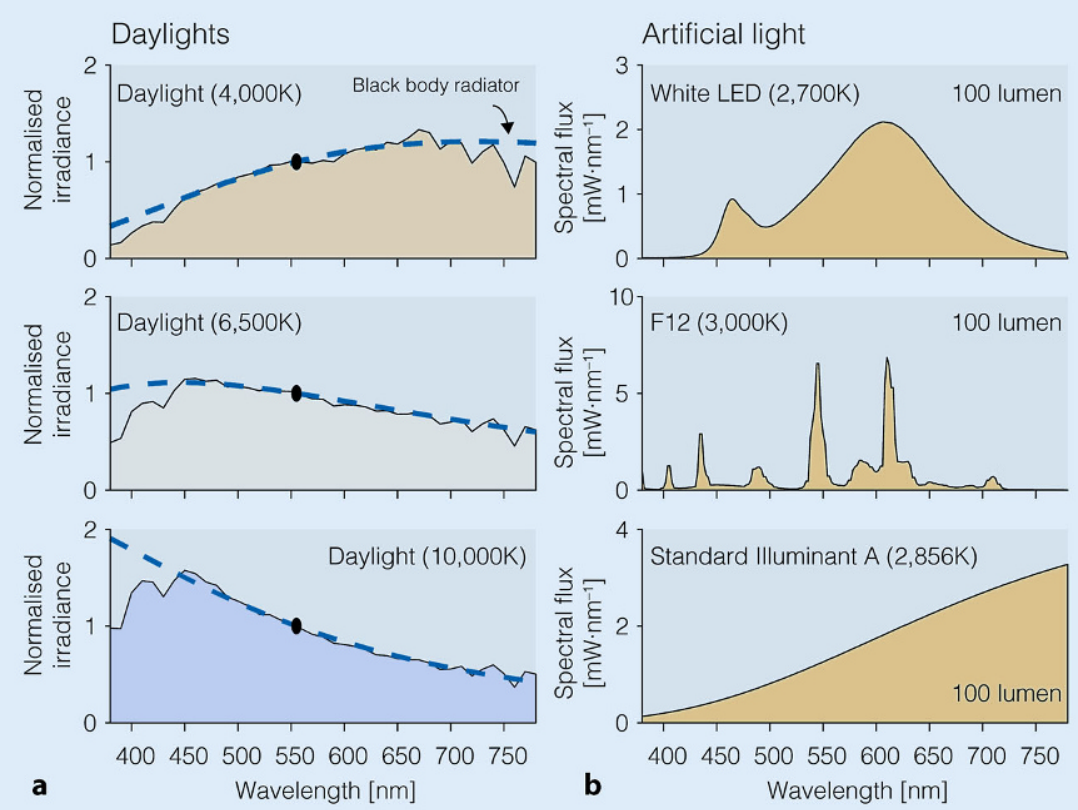

Fig. 2 - Spectral power distributions of common light sources in our environment. a Spectral power distributions of daylights at different correlated colour temperatures (CCT; $4000 \mathrm{~K} ; 6500 \mathrm{~K} ; 10,000 \mathrm{~K}$ ). Spectra are normalised to $555 \mathrm{~nm}$. b Spectral power distributions of a white LED (top), a fluorescent source at $3000 \mathrm{~K}$ (middle), and an incandescent source (tungsten-filament; $2856 \mathrm{~K}$, bottom). All three artificial sources have the same luminous flux (normalised to $100 \mathrm{~lm}$ ), and approximately the same colour temperature ( $2700-3000 \mathrm{~K}$ ), but the spectra are very different in shape and scale (see $y$ axis) ing that also the habenula in the thalamus is innervated by retinal projections $[38,110]$ which may specifically mediate mood-related non-visual effects of light.

\section{Fundamentals of light}

To understand the effects of light on the human physiology, it is important to understand light. Briefly, light is radiation in a specific range of the electromagnetic spectrum. It is best and most completely described by its spectral distribution, which quantifies the amount of energy (or the number of photons) as a function of wavelength (with visible light in the wavelength range between 380 and $780 \mathrm{~nm}$ ).

During the day, light intensities outside can reach illuminances up to $100,000 \mathrm{~lx}$ in direct sunlight and 25,000 lx in full daylight. Light intensities in closed rooms are considerably lower and standard office lighting is only $\sim 500 \mathrm{~lx}$, often lower $[37,81]$. The spectrum of daylight, which is light from the sun filtered by the atmosphere is relatively broadband in its distribution (- Fig. 2a). The availability of daylight depends on geographical location and season. In the timeframe of human evolution, it is a rather recent development that light can be available during all times of day through artificial light. Artificial light allows for illuminating indoor and outdoor spaces. It comes in many forms, e.g. incandescent, fluorescent, or light-emitting diode (LED) lighting. While light generated by these technologies may all appear "white", the underlying spectra are rather different (- Fig. 2b). The reason why many different types of spectra might have the same appearance lies in the retina. Critically, different spectra, even if they create the same visual impression, may vary in their chronobiological effects on the circadian clock.

It is important to keep in mind that there are multiple ways how light is quantified and reported in the literature in particular when focussing on its repercussions on human physiology. For example, while the absolute spectral distribution of a light is the most complete description, many investigators report the illuminance (in lux [lx]), or the 
correlated colour temperature, which is the temperature of a hypothetical blackbody radiator with the same colour as the light source in question. Unfortunately, until recently, there have been no standard quantities that experimenters were asked to report, and therefore, summarising the chronobiological and somnological literature on the effects of light remains a challenge. Recently, the Commission International de l'Eclairage (CIE), the international standard body for quantities related to light, issued a new standard containing a reference framework for quantifying the effects of light on nonvisual functions [31]. In practice, experimenters employing light as an intervention should report, at a minimum, the spectral power distribution of the light, as seen from the participant's point of view. Detailed minimum guidelines are given in [83].

\section{Photoreceptors in the retina}

In humans, the known effects of light on circadian rhythms and sleep are all, without exception, mediated by the retina. The retina is a fine layer of nerve tissue at the back of our eyes, containing specialised photoreceptors (- Fig. 3a). The so-called cones exist in the highest density in the centre of the retina-the fovea. There are three types of cones, differing in their preference for light at specific wavelengths (• Fig. 3b): The longwavelength-sensitive cones ( $\mathrm{L}$ cones), the medium-wavelength-sensitive cone ( $\mathrm{M}$ cones) and the short-wavelengthsensitive cones (S cones). Cones allow us to see colour, spatial detail and motion at light levels typical for daytime. Rods, by contrast, are suppressed at daytime light levels and only signal at light levels typical for twilight and darker. Rods are absent in the fovea, cannot distinguish between different colours and only allow for rudimentary vision.

Cones and rods are not the only photoreceptors in the retina. A small fraction of secondary neurons in the retina-the retinal ganglion cells (RGCs), which integrate information and send it to the brain via the optic nerve-express the photopigment melanopsin [62]. Melanopsin is a short-wavelength-sensitive pigment

Somnologie 2019 -23:147-156 https://doi.org/10.1007/s11818-019-00215-x

(c) The Author(s) 2019

C. Blume · C. Garbazza · M. Spitschan

Effects of light on human circadian rhythms, sleep and mood

\section{Abstract}

Humans live in a 24-hour environment, in which light and darkness follow a diurnal pattern. Our circadian pacemaker, the suprachiasmatic nuclei (SCN) in the hypothalamus, is entrained to the 24-hour solar day via a pathway from the retina and synchronises our internal biological rhythms. Rhythmic variations in ambient illumination impact behaviours such as rest during sleep and activity during wakefulness as well as their underlying biological processes. Rather recently, the availability of artificial light has substantially changed the light environment, especially during evening and night hours. This may increase the risk of developing circadian rhythm sleep-wake disorders (CRSWD), which are often caused by a misalignment of endogenous circadian rhythms and external light-dark cycles. While the exact relationship between the availability of artificial light and CRSWD remains to be established, nocturnal light has been shown to alter circadian rhythms and sleep in humans. On the other hand, light can also be used as an effective and noninvasive therapeutic option with little to no side effects, to improve sleep, mood and general well-being. This article reviews our current state of knowledge regarding the effects of light on circadian rhythms, sleep, and mood.

Keywords

Circadian rhythms · Natural light · Artificial light · Depression · Light therapy

\section{Auswirkungen von Licht auf zirkadiane Rhythmen, Schlaf und die Stimmung bei Menschen}

\section{Zusammenfassung}

Der Mensch lebt in einer 24-StundenUmgebung, in der sich Licht und Dunkelheit abwechseln. Unser zirkadianer Schrittmacher in den suprachiasmatischen Nuclei (SCN) des Hypothalamus synchronisiert unsere inneren biologischen Rhythmen mit dem Tagesverlauf des Sonnenlichts über Leitungsbahnen, die von der Netzhaut zu den SCN ziehen. Rhythmische Schwankungen in der Umgebungsbeleuchtung beeinflussen unser Verhalten, etwa den Wechsel zwischen Ruhe im Schlaf und Aktivität im Wachzustand, und dessen zugrunde liegenden biologischen Prozesse. In jüngster Zeit hat die Verfügbarkeit von künstlichem Licht die Lichtumgebung erheblich verändert, insbesondere während der Abend- und Nachtstunden. Dies kann das Risiko für die Entstehung von circadianen Schlaf-Wach-Rhythmusstörungen („circadian rhythm sleep-wake disorders", CRSWD) erhöhen, die oft durch eine Fehlausrichtung bzw. einen Versatz zwischen endogenen tageszeitlichen Rhythmen und dem externen Hell-Dunkel-Zyklus verursacht werden. Zwar ist der genaue Zusammenhang zwischen der Verfügbarkeit von künstlichem Licht und CRSWD noch nicht geklärt, doch es hat sich gezeigt, dass nächtliches Licht den zirkadianen Rhythmus und den Schlaf beim Menschen verändert. Andererseits kann Licht auch als effektive, nichtinvasive Therapieoption mit geringen bis keinen Nebenwirkungen eingesetzt werden, um Schlaf, Stimmung und Allgemeinbefinden zu verbessern. Der vorliegende Beitrag gibt einen Überblick über den aktuellen Wissensstand hinsichtlich der Auswirkungen von Licht auf zirkadiane Rhythmen, Schlaf und Stimmung.

\section{Schlüsselwörter}

Zirkadiane Rhythmen · Natürliches Licht . Künstliches Licht · Depression · Lichttherapie with a peak spectral sensitivity near around $480 \mathrm{~nm}$ [4], rendering some RGCs intrinsically photosensitive [79]. These intrinsically photosensitive retinal ganglion cells (ipRGCs) are thought to mediate most effects of light on the circadian clock. However, ipRGCs are not independent of rod and cone input.
Rather, they also receive information from these receptors, suggesting that ipRGCs indeed act as "integrators of information" regarding the light environment across a wide range of wavelengths and light levels. Surprisingly, the input from the $S$ cones into the ipRGCs has a negative sign [32]. In humans, this 


\section{Reviews}

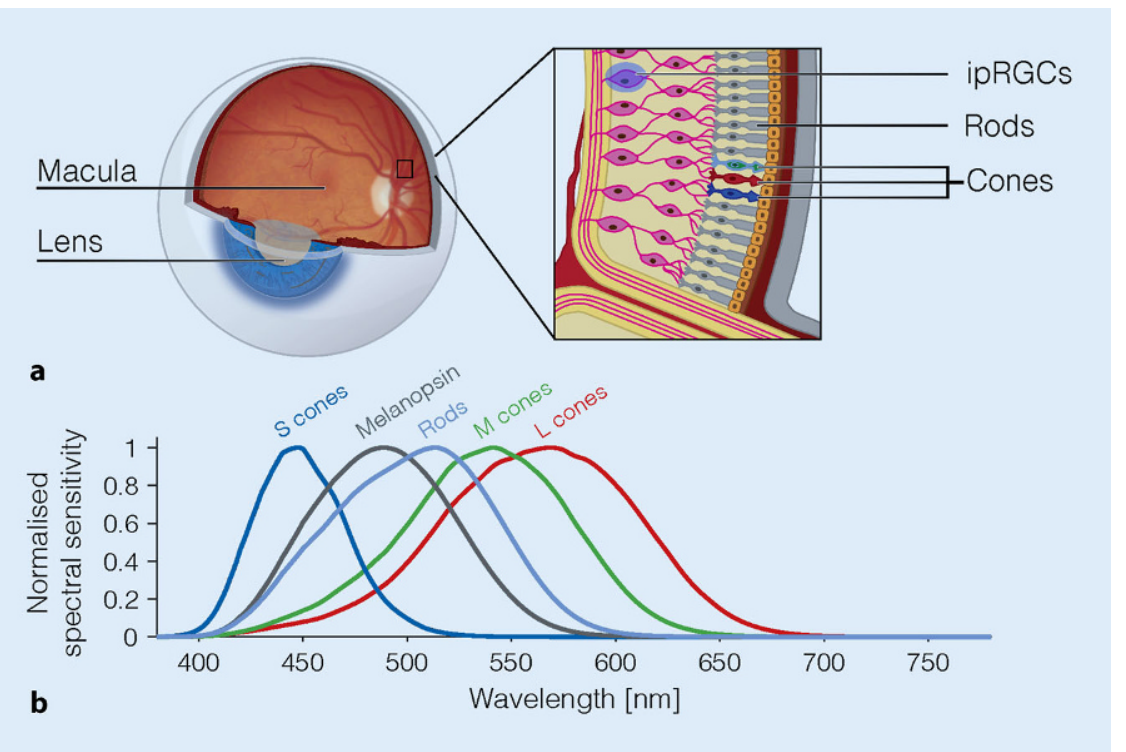

Fig. $3 \Delta$ Overview of the retina photoreceptors. a Schematic view of the eye with the retina at the back of the eye (the fundus), containing cones, rods and the intrinsically photosensitive retinal ganglion cells (ipRGCs) expressing the photopigment melanopsin. b Spectral sensitivities of the photoreceptors in the human eye

has the paradoxical consequence that increases in $S$ cone activation lead to a dilation of the pupil $[80,100]$, which is also controlled by the ipRGCs.

It has long been thought that cones and rods mediate what is typically considered "vision" (seeing colour, motion, spatial detail), and that melanopsin mediates the "other", non-visual effects of light, i.e. melatonin suppression, circadian phase shifting, and alertness. However, at second sight, this dichotomy breaks down. There is now converging evidence that melanopsin signals reach the primary visual cortex (V1) [82], where they may contribute to and modulate our visual perception $[20,25,109]$.

It is important to keep in mind that the retinal photoreceptors experience an altered version of the light relative to the cornea, the front surface of the eye. This is because the eye itself contains filters. In the centre of the retina, this includes the macular pigment, which is present in the fovea but drops off in the peripheral retina. More importantly for ipRGCs, the crystalline lens and ocular media filter out short-wavelength light. This natural "blue-blocking" filter increases density with increasing age, with less and less short-wavelength light reaching the retina.
The system mediating melatonin suppression has a spectral sensitivity that is broadly consistent with the spectral sensitivity of melanopsin $[17,60,88]$. Similarly, the spectral sensitivity of circadian phase shifting shows its maximal effect near the peak spectral sensitivity of melanopsin [101]. However, this does not imply that cones and rods may not participate in these non-visual effects of light. Indeed, there is evidence that cones do contribute, though at a different time scale than the ipRGCs [42].

The effects of light on the phase of the circadian clock depend on the timing of light exposure. This is formally summarised in the phase response curve (PRC), which describes the amount of phase shift (in minutes and hours) achieved by exposure of light at a given circadian phase. Roughly speaking, the effect of morning light is that it advances the clock, while evening and night light delays the clock. The human circadian system integrates across multiple light exposures as short as five minutes [48], even intermittent bright light exposure can shift the circadian phase $[43,66]$. It has been shown that under certain circumstances, a train of very brief flashes light flashes on the millisecond scale can cause circadian phase shifts which are larger than those caused by continuous light $[59,108]$.

Both melatonin suppression and circadian phase shifts are modulated by the "photic history", i.e. the amount of light seen during the day $[27,44,77]$. The longterm adaptive influences of the "spectral diet" in the real world remain an important area of investigation [93].

\section{Effects of light on sleep} gated extensively in human circadian and sleep research: (1) the acute suppression of melatonin in response to light exposure and (2) the ability of light exposure to shift circadian phase. However, these two effects are not arising from a unitary pathway resulting in a direct relationship between melatonin suppression and phase shifts. There is now accruing evidence that they may be indeed separable [63]. As a consequence, one should not be used as a proxy for the other [106].

The human sleep-wake cycle, that is periods of sleep during the night and wakefulness during the day, is one of the most prominent examples of a circadian behavioural pattern. It results from the interaction between two factors: the circadian drive for wakefulness and the homeostatic sleep pressure. The interaction between this circadian "process C" and the homeostatic "process S" has been conceptualised in the widely known "two-

process model of sleep" $[13,15]$, which 


\begin{tabular}{|c|c|}
\hline $\begin{array}{l}\text { Ophthalmological } \\
\text { examination } \\
\text { recommended in the } \\
\text { following conditions }\end{array}$ & $\begin{array}{l}\text { - Pre-existing diseases of the retina or the eye, e.g. retinal detachment, } \\
\text { retinitis pigmentosa, glaucoma } \\
\text { - Systematic diseases affecting the retina, e.g. diabetes mellitus } \\
\text { - Previous cataract surgery or lens removal } \\
\text { - Elderly people (increased risk of age-related macular degeneration; } \\
\text { AMD) }\end{array}$ \\
\hline $\begin{array}{l}\text { Caution needed } \\
\text { by patients taking } \\
\text { following } \\
\text { photosensitizing } \\
\text { drugs }\end{array}$ & $\begin{array}{l}\text { - Neuroleptics (phenothiazines) } \\
\text { - Antidepressants (imipramine) } \\
\text { - Mood stabilizers (lithium) } \\
\text { - Diuretics (hydrochlorothiazide) } \\
\text { - 8-methoxypsoralen } \\
\text { - Cardiac medications (propranolol, amiodarone) } \\
\text { - Chloroquine } \\
\text { - Antibiotics (tetracycline) } \\
\text { - "Natural medicines" (melatonin, St. John's Wort) }\end{array}$ \\
\hline
\end{tabular}

accounts for the timing and intensity of sleep in many experimental settings. Indeed, in well-controlled studies the circadian pacemaker in the $\mathrm{SCN}$ and the sleep homeostat have been shown to interact in a fashion designed to allow for consolidated periods of wakefulness and sleep during day and night, respectively (e.g. [35]). Specifically, the activity of the circadian pacemaker is aligned to counteract the increasing sleep pressure resulting from sustained wakefulness during daytime. Likewise, the nocturnal increase in circadian sleep tendency counteracts the decrease in sleep propensity resulting from accumulated sleep thereby supporting a consolidated phase of nocturnal sleep.

As outlined above, light is the key zeitgeber in the circadian system and interacts with the master clock in the $\mathrm{SCN}$ via non-image-forming pathways connecting retina and SCN. Unsurprisingly, light therefore also affects sleep. Natural daylight at high intensities as experienced outside buildings has previously been shown to (1) advance the timing of sleep to earlier hours, (2) affect the duration of sleep, and (3) improve sleep quality. More precisely, the phase-advancing effects of daylight have for example been reported by Roenneberg and colleagues [67] who, using questionnaire data, found that each additional hour spent outdoors advanced sleep by $\sim 30 \mathrm{~min}$. Despite light being the strongest zeitgeber, this phase-advance could also result from physical exercise during daytime [102, 105], which is often confounded with time spent outdoors. The relative contributions of light and physical activity remain to be determined. Moreover, light exposure during the day has also been shown to affect sleep duration. Here, shorter daylight exposure and longer nights are associated with a longer biological night as indexed by the duration of melatonin secretion, and thus longer sleep duration [85, 94, 95], which may also reflect a seasonality effect [104]. Likewise, exposure to daylight has been shown to increase sleep duration, possibly by advancing sleep timing [16]. Beyond this, sleep quality is also related to light exposure during the day. Several studies report that daytime exposure to white light enriched in shortwavelength content was associated with increased evening fatigue [91], and sleep quality [16, 39, 91], decreased sleep-onset latency [39], and increased slow-wave sleep accumulation [92], which is related to the dissipation of the homeostatic sleep pressure $[1,14,34]$. However, also the timing of light exposure seems to matter for sleep. In this context, Wams and colleagues [92] report that participants with later exposure to light $>10 \mathrm{~lx}$ had more nocturnal awakenings and less slow-wave sleep. In sum, research seems to agree that daylight (at high intensities) is beneficial for sleep.

\section{Exposure to artificial lighting, smartphones and visual display units}

In addition to natural daylight, humans are nowadays also exposed to a considerable amount of artificial light. This is particularly the case in the evening hours, i.e. when the circadian system is most sensitive to light-induced phase delays. Thereby, artificial light can delay the timing of the circadian clock and thus sleep [102]. Indeed, light from LED screens has repeatedly been suggested to interfere with sleep and the physiological processes involved (e.g., melatonin secretion [24]). Chang and colleagues [26] for example found that reading a book from an e-reader for four hours before sleep increased sleep onset latency, reduced evening sleepiness, melatonin secretion as well as next-morning alertness, and delayed the timing of the biological clock, which is also in line with other findings $[72,107]$. It should be noted though that exposure to the "circadian-active" light source was very long in these studies (4-6.5 h) and it is unclear whether the same results can be expected for shorter exposures.

Evaluating sleep objectively with electroencephalography (EEG), Münch and colleagues [58] found that exposure to short-wavelength light for two hours starting $3 \mathrm{~h}$ before habitual bedtime first lead to decreased slow wave activity (SWA) and thus shallower sleep. From this, the authors concluded that the alerting effects of short-wavelength light persist into sleep, which is in line with findings by Chellappa and colleagues [28], who reported a decrease in homeostatic sleep pressure following short-wavelength light exposure in the evening. However, short-wavelength light exposure in the evening was also associated with increased SWA later during the night, suggesting a possible compensatory mechanism [58].

Also, the effects of evening light exposure do not seem to be independent from exposure during the preceding day. More specifically, Rångtell and colleagues [64] examined the effects of reading a novel on a tablet computer $(\sim 102 \pm 41 \mathrm{~lx}, 7718 \mathrm{~K})$ vs. in a physical book $(\sim 67 \pm 50 \mathrm{~lx}, 2674 \mathrm{~K})$ for two hours following prolonged $(6.5 \mathrm{~h})$ exposure to bright light $(\sim 569 \mathrm{~lx}, 3149 \mathrm{~K})$ between 2:30 pm and $9 \mathrm{pm}$. Contrasting other findings, the light from the tablet did not suppress melatonin or alter subjective and objective sleep parameters. Note though that also exposure was shorter 


\section{Infobox 1 Smartphones and sleep}

Smartphone use may delay sleep onset. One factor is the light emitted by their screens, but another may also be its entertaining character or related psychological effects, or both. Using the "night shift" mode of modern smartphones, the colour balance of the screen can be shifted to "warmer" and orangeish colours depleted in short-wavelength light. On a recent iPhone 7 , this amounts to a reduction of melanopsin activation by $67 \%$ at full display brightness. This might seem like a large reduction at first, though by simply dimming the smartphone to its minimum level, the melanopsin activation can be reduced to less than $1 \%$ of the activation at maximum display brightness. Whether or not the "night shift mode" has an appreciable effect on the circadian system and how it interacts with other properties of smartphone use is currently not known. Recent research using so-called metameric displays, which do not differ in their appearance but only differ in the amount that they stimulate melanopsin, show that the non-visual properties of light can be modulated independently of visual appearance $[3,78]$.

than in studies that reported significant effects $[26,72,107]$.

Several studies have reported that smartphone ownership and use before bedtime may be associated with more self-reported sleeping problems [74], decreased sleep efficiency, longer sleep onset latency and poor sleep quality [29], and delays sleep thereby also shortening sleep duration [29, 50, 74]. Modern smartphones contain a "night shift" feature changing the colour balance in the evening hours ( $\bullet$ Infobox 1 for details). How much of the reported detrimental effect of smartphone use on sleep is due to light per se, or to some other feature (e.g. psychological engagement), is currently not known.

\section{Effects of light on mood}

Mood variations have been shown to be influenced by a complex and non-additive interaction between circadian phase and the duration of prior wakefulness. Specifically, relatively moderate changes in the timing of the sleep-wake cycle can significantly modulate mood [11].
Light can affect mood in several ways: by directly modulating the availability of neurotransmitters such as serotonin, which is involved in mood regulation, and by entraining and stabilising circadian rhythms, thereby addressing circadian desynchronisation and sleep disorders, which are rather common in people suffering from mental disorders. Therefore, in the last decades, light as an intervention-light therapy-has found an increasingly widespread use for treating mood and other psychiatric disorders $[73,97]$.

The precise mechanisms by which light exerts a positive influence on mood are currently not known though. In addition to the circadian effects of light mediated via the SCN, a pathway from the retina to the habenula has recently been found to be involved in mediating effects of light on mood in animal models $[38,110]$. This pathway, connecting some ipRGCs with the habenula and bypassing the SCN altogether, has been suggested to specifically mediate light-induced alterations in mood [38]. Although it is unclear to what extent these findings can be applied to humans, imaging studies at least suggest that the human habenula is also sensitive to modulations of ambient light [46]. More research is needed to identify the mechanisms underlying light therapy.

In the following, we will provide an overview of the major clinical applications of light therapy and a brief guide to its use in daily clinical practice.

\section{Light therapy as an intervention in psychiatric conditions}

Bright light therapy (BLT) for mood disorders was first introduced for the treatment of Seasonal Affective Disorder (SAD) in 1984 [68]. SAD is a subtype of depression characterised by strong seasonal variations in mood states. BLT is nowadays established as first-line treatment for SAD [61, 75] leading to an amelioration of symptoms after a few days of treatment. Light therapy is also effective as second-line treatment for non-seasonal depression, although it usually takes longer (2-5 weeks) than in SAD to achieve a therapeutic effect $[2,75$,
87]. BLT, especially in combination with selective serotonin reuptake inhibitors (SSRIs), can accelerate the clinical improvement and lead to significantly fewer residual symptoms $[7,53]$. In patients with chronic depression, BLT has been shown to lead to remarkable remission rates compared to placebo [41] and represents a valid therapeutic option also in gender-related mood disorders, such as premenstrual dysphoric disorder and perinatal depression $[47,96]$.

BLT can be delivered by special, commercially available therapy lamps, which operate at illuminance levels between 7000 and 10,000 lx, but natural daylight during a regular one-hour morning walk has been shown to be similarly effective [99]. In populations who suffer from depressive mood resulting from of a lack of exposure to natural daylight due to, for example, working duties in shift workers, patients with altered sleep-wake rhythms (e.g. delayed sleep-wake phase disorder), or social withdrawal (patients with psychiatric disorders, elderly people), BLT provides an effective treatment and valid alternative to pharmacological approaches [98].

Not only "active" chronotherapeutic approaches, but also an adequate architectural design of the light environment may have relevant clinical implications for psychiatric patients. The availability of light in hospital rooms has been shown to decrease the length of stay of depressed patients in a clinic [6]. Moreover, retrospective analyses revealed a threeday shorter hospitalisation in bipolar depressed inpatients exposed to natural light in sunny hospital rooms compared to those in darker rooms [8].

\section{Light therapy as an intervention in other medical conditions}

In recent years, light therapy has been increasingly implemented as an adjunctive therapy for several other medical conditions. In patients with anorexia or bulimia nervosa, light not only improves mood but also helps to better control specific disease-related symptoms (for a review see $[5,49]$ ). Well-controlled longitudinal studies have demonstrated that light not only has antidepressant effects in 
age-related depression, but can also slow down the progressive cognitive decline in dementia [52,65]. More generally, due to its rhythm-synchronising properties and its enhancing effects on sleep quality and wakefulness, BLT is becoming an important tool in geriatric care, to treat sleepwake disturbances and reduce general listlessness [76]. The stabilising effects of light also make BLT a useful additional treatment in adult attention deficit hyperactivity disorder (ADHD) [69], borderline personality disorder [19], and other conditions characterised by sleep-wake disruption, such as schizophrenia [18] or neurodegenerative diseases [103]. New applications are also emerging in internal medicine, e.g. in intensive care units, where day and night differences in lighting are often severely attenuated, which may result in patients developing a fragmented sleep-wake cycle with a negative impact on their recovery [36]. Studies have also demonstrated beneficial effects of BLT in patients with sleep-wake abnormalities after renal transplantation [21] or in cirrhotic patients [33], as well as in severely brain-injured patients in postcomatose states $[9,10]$, and Parkinson's disease [90]. Finally, one of the most common applications of light, often in combination with exogenous melatonin, is found in sleep medicine $[70,71]$ for the treatment of specific circadian rhythm sleep-wake disorders (CRSWD), including advanced and delayed sleep-wake phase disorder, jet lag, shift work, sighted non-24 and irregular sleep-wake phase disorder (for diagnostic criteria see [89]).

\section{Light therapy in practice}

\section{Timing, frequency and duration of light therapy sessions}

The antidepressant effect of light is most pronounced when it is administered in the early morning hours [86, 97]. For CRSWD, the timing of therapeutic light exposure depends on the type of circadian disturbance and the direction of phase shift (advance or delay) to be pursued in order to achieve circadian resynchronisation. Therefore, a reliable marker of circadian phase should be first assessed to identify the phase position and then determine the timing of light treatment. The gold standard for measuring circadian phase is obtained by quantifying the so-called dim light melatonin onset (DLMO), i.e. the time at which melatonin levels rise above baseline, indicating that melatonin secretion has started. However, implementing DLMO assessment in the clinical practice remains difficult due to the limited availability of equipped centres that perform melatonin analyses and the costs of this diagnostic procedure, which are currently not reimbursed by health insurances in most European countries.

BLT is particularly effective when exposure to light occurs regularly, i.e. on a daily basis, for at least 30-60 min. Therefore, it is commonly performed in a domestic setting, which facilitates the required compliance, especially regarding timing, frequency, and duration of

Hier steht eine Anzeige. 
the treatment sessions. Disease relapses due to lacking therapeutic adherence depend on the underlying pathological condition: while SAD may rapidly reappear after a short therapy break, isolated days without light therapy are unlikely to have any negative consequences on circadian rhythm stabilisation in CRSWD, if regular sleep-wake schedules are maintained.

\section{Light therapy devices}

Most light therapy devices on the market are suitable for clinical use. They reach a corneal illuminance of 7000-10,000 lx at a viewing distance of $20-35 \mathrm{~cm}$ and are equipped with a protective screen with almost complete UV filtering. Ideally designed devices illuminate the patient diagonally from above with an irradiation angle of $\sim 15^{\circ}$. A bevelled light surface prevents annoying glare and allows simultaneous reading, thus being better tolerated. To obtain a therapeutic effect, it is not necessary to look directly into the light source, but the eyes must be open. Available light therapy glasses, which even allow mobility during the sessions, also partially meet the required criteria of sufficient light illuminance. However, most of them have not yet been evaluated in large, randomised clinical trials. Another alternative to receive light in the early morning hours is through dawn simulators. These devices start providing a relatively weak light signal about $90 \mathrm{~min}$ before wake-up time, which, covering the patients' final sleep cycle, then gradually increases in intensity from about $0.001 \mathrm{~lx}$ to about $300 \mathrm{~lx}$. However, also for these devices, the design plays an important role, as a diffuse, wide lighting area is necessary to reach the sleeper in the different lying positions. For the same reason, other types of available miniature lighting devices are not recommended because of their small luminous field [98].

\section{Adverse reactions}

Adverse reactions to light therapy include eye irritation, blurry vision, grumpiness, headache or nausea after light exposure. However, these effects are usually rare and lessen after a few days of treatment or under reduced dosage [98]. Isolated cases of increased excitability following light therapy have been reported in patients with bipolar disorder [98]. Occurring sleep problems such as problems related to initiating sleep when light is administered in the evening, or early morning awakenings when light is administered in the morning, are mostly related to an unappropriated time of light exposure and can be quickly resolved by modifying the timing of light therapy sessions.

\section{Contraindications}

Some relative contraindications should be taken into account when considering light therapy in patients with ophthalmological diseases or taking photosensitising drugs. These are summarised in - Table 1; [22, 40].

\section{Summary}

Light not only enables us to see fine detail, colour and motion, but also exerts nonvisual effects on circadian rhythms, sleep and mood. Light at the wrong time may disrupt circadian rhythms and sleep, but in the form of light therapy, light exposure can be used as an intervention for psychiatric and other medical conditions.

\section{Corresponding address}

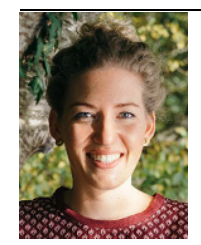

\section{Dr. Christine Blume}

Centre for Chronobiology, Psychiatric Hospital of the University of Basel (UPK) Basel, Switzerland Christine.Blume@sbg.ac.at

Dr. med. Corrado Garbazza
Centre for Chronobiology,
Psychiatric Hospital of the
University of Basel (UPK)
Basel, Switzerland
Corrado.Garbazza@upk.ch

Funding. C. Blume is supported by an Erwin Schroedinger Fellowship from the Austrian Science Fund (FWF J-4243), a grant from the Freiwillige Akademische Gesellschaft (FAG) Basel, and a grant from the Psychiatric Hospital of the University of Basel (UPK). C. Garbazza is supported by a grant of the Swiss National Science Foundation (SNSF 160250). M. Spitschan is supported by a Sir Henry Wellcome Trust Fellowship (Wellcome Trust 204686/Z/16/Z) and Junior Research Fellowship from Linacre College, University of Oxford. Open access funding provided by Austrian Science Fund (FWF).

\section{Compliance with ethical guidelines}

Conflict of interest C. Blume, C. Garbazza and M. Spitschan declare that they have no relevant competing interests.

For this review article no studies with human participants or animals were performed by any of the authors.

Open Access. This article is distributed under the terms of the Creative Commons Attribution 4.0 International License (http://creativecommons.org/licenses/by/ 4.0/), which permits unrestricted use, distribution, and reproduction in any medium, provided you give appropriate credit to the original author(s) and the source, provide a link to the Creative Commons license, and indicate if changes were made.

\section{References}

1. Achermann P, Dijk D-J, Brunner DP et al (1993) A model of human sleep homeostasis based on EEG slow-wave activity: Quantitative comparison of data and simulations. Brain Res Bull 31:97-113

2. Al-Karawi D, Jubair L (2016) Bright light therapy for nonseasonal depression: meta-analysis of clinical trials. J Affect Disord 198:64-71

3. Allen AE, Hazelhoff EM, Martial FP et al (2018) Exploiting metamerism to regulate the impact of a visual display on alertness and melatonin suppression independent of visual appearance. Sleep. https://doi.org/10.1093/sleep/zsy100

4. Bailes HJ, Lucas RJ (2013) Human melanopsin forms a pigment maximally sensitive to blue light (lambdamax approximately $479 \mathrm{~nm}$ ) supporting activation of $\mathrm{G}(\mathrm{q} / 11)$ and $\mathrm{G}(\mathrm{i} / \mathrm{o})$ signalling cascades. Proc Biol Sci 280:20122987

5. Beauchamp MT, Lundgren JD (2016) A systematic review of bright light therapy for eating disorders. Prim Care Companion CNSDisord. https://doi.org/ 10.4088/PCC.16r02008

6. Beauchemin KM, Hays P (1996) Sunny hospital rooms expedite recovery from severe and refractory depressions. J Affect Disord 40:49-51

7. Benedetti F, Barbini B, Fulgosi MC et al (2005) Combined total sleep deprivation and light therapy in the treatment of drug-resistant bipolar depression: acute response and long-term remission rates. J Clin Psychiatry 66:1535-1540

8. Benedetti F, Colombo C, Barbini B et al (2001) Morning sunlight reduces length of hospitalization in bipolar depression. J Affect Disord 62:221-223

9. Blume C, Angerer M, Raml M et al (2019) Healthier rhythm, healthier brain? Integrity of circadian 
melatonin and temperature rhythms relates to the clinical state of brain-injured patients. Eur J Neurol. https://doi.org/10.1111/ene.13935

10. Blume C, Lechinger J, Santhi N et al (2017) Significance of circadian rhythms in severely brain-injured patients: a clue to consciousness? Neurology. https://doi.org/10.1212/WNL. 0000000000003942

11. Boivin DB, Czeisler CA, Dijk D-J et al (1997) Complex interaction of the sleep-wake cycle and circadian phase modulates mood in healthy subjects. Arch Gen Psychiatry 54:145-152

12. Bollinger T, Schibler U (2014) Circadian rhythms - from genes to physiology and disease. Swiss Med Wkly. https://doi.org/10.4414/smw. 2014.13984

13. Borbély AA (1982) A two process model of sleep regulation. Human Neurobiology 1(3):195-204

14. Borbély AA, Achermann P, Trachsel L et al (1989) Sleep initiation and initial sleep intensity: interactions of homeostatic and circadian mechanisms. JBiol Rhythms 4:37-48

15. Borbély AA, Daan S, Wirz-Justice A et al (2016) The two-process model of sleep regulation: a reappraisal. JSleep Res 25:131-143

16. Boubekri M, Cheung IN, Reid KJ et al (2014) Impact of windows and daylight exposure on overall health and sleep quality of office workers: a casecontrol pilot study. JClin Sleep Med 10:603-611

17. Brainard GC, Hanifin JP, Greeson JM et al (2001) Action spectrum for melatonin regulation in humans: evidence for a novel circadian photoreceptor. JNeurosci 21:6405-6412

18. Bromundt V, Köster M, Georgiev-Kill A et al (2011) Sleep-wake cycles and cognitive functioning in schizophrenia. Br JPsychiatry 198:269-276

19. Bromundt V, Wirz-Justice A, Kyburz S et al (2013) Circadian sleep-wake cycles, well-being, and light therapy in borderline personality disorder. J Pers Disord 27:680-696

20. Brown TM, Tsujimura S, Allen AE et al (2012) Melanopsin-based brightness discrimination in mice and humans. Curr Biol 22:1134-1141

21. Burkhalter $H$, Wirz-Justice $A$, Denhaerynck $K$ et al (2015) The effect of bright light therapy on sleep and circadian rhythms in renal transplant recipients: a pilot randomized, multicentre waitlist controlled trial. Transpl Int 28:59-70

22. Cajochen C (2013) Chronobiologie: Licht-und Wachtherapie bei psychiatrischen Erkrankungen. Psych Up2date 7:173-184

23. Cajochen C, Kräuchi K, Wirz-Justice A (2003) Role of melatonin in the regulation of human circadian rhythms and sleep. J Neuroendocrinol 15:432-437

24. Cajochen C, Munch M, Kobialka S et al (2005) High sensitivity of human melatonin, alertness, thermoregulation, and heart rate to short wavelength light. J Clin Endocrinol Metab 90:1311-1316

25. Cao D, Chang A, Gai S (2018) Evidence for an impact of melanopsin activation on unique white perception. J Opt Soc Am A Opt Image Sci Vis 35:B287-B291

26. Chang A-M, Aeschbach D, Duffy JF et al (2015) Evening use of light-emitting eReaders negatively affects sleep, circadian timing, and next-morning alertness. Proc Natl Acad Sci USA 112:1232-1237

27. Chang AM, Scheer FA, Czeisler CA (2011) The human circadian system adapts to prior photic history. JPhysiol 589:1095-1102

28. Chellappa SL, Steiner R, Oelhafen P et al (2013) Acute exposure to evening blue-enriched light impacts on human sleep. J Sleep Res 22:573-580
29. Christensen MA, Bettencourt L, Kaye L et al (2016) Direct measurements of smartphone screen-time: relationships with demographics and sleep. PLoS ONE 11:e165331

30. Ciarleglio C, Resuehr H, Mcmahon D (2011) Interactions of the serotonin and circadian systems: nature and nurture in rhythms and blues. Neuroscience 197:8-16

31. Commision Internationale d'Eclairage [CIE] (2018) CIE system for metrology of optical radiation for ipRGC-influenced responses to light. CIE Central Bureau, Vienna, Austria

32. Dacey DM, Liao HW, Peterson BB et al (2005) Melanopsin-expressing ganglion cells in primate retina signal colour and irradiance and project to the LGN. Nature 433:749-754

33. De Rui M, Middleton B, Sticca A et al (2015) Sleep and circadian rhythms in hospitalized patients with decompensated cirrhosis: effect of light therapy. Neurochem Res 40:284-292

34. Dijk D-J, Czeisler CA (1995) Contribution of the circadian pacemaker and the sleep homeostat to sleep propensity, sleep structure, electroencephalographic slow waves, and sleep spindle activity in humans. J Neurosci 15:3526-3538

35. Dijk D-J, Czeisler CA (1994) Paradoxical timing of the circadian rhythm of sleep propensity serves to consolidate sleep and wakefulness in humans. Neurosci Lett 166:63-68

36. Engwall M, Fridhl,Johansson Letal (2015) Lighting, sleep and circadian rhythm: an intervention study in the intensive care unit. Intensive Crit Care Nurs 31:325-335

37. European Union (2011) European Lighting Standard. In: EN12464-1:2011.

38. Fernandez DC, Fogerson PM, Lazzerini Ospri L et al (2018) Light affects mood and learning through distinct retina-brain pathways. Cell 175:71-84.e18

39. Figueiro MG, Steverson B, Heerwagen J et al (2017) The impact of daytimelight exposures on sleep and mood in office workers. Sleep Health 3:204-215

40. Gallin PF, Terman M, Reme CE et al (1995) Ophthalmologic examination of patients with seasonal affective disorder, before and after bright light therapy. Am J Ophthalmol 119:202-210

41. Goel N, Terman M, Terman JS et al (2005) Controlled trial of bright light and negative air ions for chronic depression. Psychol Med 35:945-955

42. Gooley JJ, Rajaratnam SM, Brainard GC et al (2010) Spectral responses of the human circadian system depend on the irradiance and duration of exposure to light. Sci Transl Med 2:31 ra33

43. Gronfier C, Wright KP Jr, Kronauer RE et al (2004) Efficacy of a single sequence of intermittent bright light pulses for delaying circadian phase in humans. Am J Physiol Endocrinol Metab: https:// doi.org/10.1152/ajpendo.00385.2003

44. Hebert M, Martin SK, Lee Cetal (2002) The effects of prior light history on the suppression of melatonin by light in humans. J Pineal Res 33:198-203

45. Ibuka N, Kawamura H (1975) Loss of circadian rhythm in sleep-wakefulness cycle in the rat by suprachiasmatic nucleus lesions. Brain Res Brain Res Protoc 96:76-81

46. Kaiser C, Kaufmann C, Leutritz T et al (2019) The human habenula is responsive to changes in luminance and circadian rhythm. Neuroimage 189:581-588

47. Krasnik C, Montori VM, Guyatt GH et al (2005) The effect of bright light therapy on depression associated with premenstrual dysphoric disorder. Am JObstet Gynecol 193:658-661

48. Kronauer RE, Forger DB, Jewett ME (1999) Quantifying human circadian pacemaker response to brief, extended, and repeated light stimuli over the phototopic range. J Biol Rhythms 14:501-516 49. Lam RW, Goldner EM, Solyom L et al (1994) A controlled study of light therapy for bulimia nervosa. Am J Psychiatry 151:744

50. Lemola S, Perkinson-Gloor N, Brand S et al (2015) Adolescents' electronic media use at night, sleep disturbance, and depressive symptoms in the smartphone age. J Youth Adolesc 44:405-418

51. Lewy AJ, Wehr TA, Goodwin FK et al (1980) Light suppresses melatonin secretion in humans. Science 210:1267-1269

52. Lieverse R, Van Someren EJ, Nielen MM et al (2011) Bright light treatment in elderly patients with nonseasonal major depressive disorder: a randomized placebo-controlled trial. Arch Gen Psychiatry 68:61-70

53. Martiny K (2004) Adjunctive bright light in nonseasonal major depression. Acta Psychiatr Scand 110:7-28

54. Meyer-Bernstein E, Morin L (1996) Differential serotonergic innervation of the suprachiasmatic nucleus and the intergeniculate leaflet and its role in circadian rhythm modulation. J Neurosci 16:2097-2111

55. Mohawk JA, Green CB, Takahashi JS (2012) Central and peripheral circadian clocks in mammals. Annu Rev Neurosci 35:445-462

56. Moore RY (2007) Suprachiasmatic nucleus in sleep-wake regulation. Sleep Med 8:27-33

57. Mouret J, Coindet J, Debilly G et al (1978) Suprachiasmatic nuclei lessions in the rat: alterations in sleep circadian rhythms. Electroencephalogr Clin Neurophysiol 45:402-408

58. Münch M, Kobialka S, Steiner R et al (2006) Wavelength-dependent effects of evening light exposure on sleep architecture and sleep EEG power density in men. Am J Physiol Regul Integr Comp Physiol 290:R1421-R1428

59. Najjar RP, Zeitzer JM (2016) Temporal integration of light flashes by the human circadian system. J Clin Invest 126:938-947

60. Nowozin C, Wahnschaffe A, Rodenbeck A et al (2017) Applying Melanopic lux to measure biological light effects on Melatonin suppression and subjective sleepiness. Curr Alzheimer Res 14:1042-1052

61. Partonen T, Pandi-Perumal S (2010) Seasonal affective disorder: practice and research. Oxford University Press, Oxford, UK

62. Provencio I, Rodriguez IR, Jiang G et al (2000) A novel human opsin in the inner retina. J Neurosci 20:600-605

63. Rahman SA, Hilaire StMA, Gronfier C et al (2018) Functional decoupling of melatonin suppression and circadian phase resetting in humans. JPhysiol 596:2147-2157

64. Rångtell FH, Ekstrand $E$, Rapp L et al (2016) Two hours of evening reading on a self-luminous tablet vs. reading a physical book does not alter sleep after daytime bright light exposure. Sleep Med 23:111-118

65. Riemersma-Van Der Lek RF, Swaab DF, Twisk J et al (2008) Effect of bright light and melatonin on cognitive and noncognitive function in elderly residents of group care facilities: a randomized controlled trial. JAMA 299:2642-2655

66. Rimmer DW, Boivin DB, Shanahan TL et al (2000) Dynamic resetting of the human circadian pacemaker by intermittent bright light. Am J Physiol Regul Integr Comp Physiol 279:R1574-R1579

67. Roenneberg T, Wirz-Justice A,Merrow M (2003) Life between clocks: daily temporal patterns of human Chronotypes. JBiol Rhythms 18:80-90 
68. Rosenthal NE, Sack DA, Gillin JC et al (1984) Seasonal affective disorder: a description of the syndrome and preliminary findings with light therapy. Arch Gen Psychiatry 41:72-80

69. Rybak YE, Mcneely HE, Mackenzie BE et al (2006) An open trial of light therapy in adult attentiondeficit/hyperactivity disorder. J Clin Psychiatry 67:1527-1535

70. Sack RL, Auckley D, Auger RR et al (2007) Circadian rhythm sleep disorders: part l, basic principles, shift work and jet lag disorders. Sleep 30:1460-1483

71. Sack RL, Lewy AJ, Hughes RJ (1998) Use of melatonin for sleep and circadian rhythm disorders. Ann Med 30:115-121

72. Santhi N, Thorne HC, Van Der Veen DR et al (2012) The spectral composition of evening light and individual differences in the suppression of melatonin and delay of sleep in humans. J Pineal Res 53:47-59

73. Schwartz RS, Olds J (2015) The psychiatry of light. Harv Rev Psychiatry 23:188-194

74. Schweizer A, Berchtold A, Barrense-Dias Y et al (2017) Adolescents with a smartphone sleep less than their peers. Eur J Pediatr 176:131-136

75. Sheaves B, Freeman D, Isham L et al (2018) Stabilising sleep for patients admitted at acute crisis to a psychiatric hospital (OWLS): an assessorblind pilot randomised controlled trial. Psychol Med 48:1694-1704

76. Shochat T, Martin J, Marler M et al (2000) Illumination levels in nursing home patients: effects on sleep and activity rhythms. J Sleep Res 9:373-379

77. Smith KA, Schoen MW, Czeisler CA (2004) Adaptation of human pineal melatonin suppression by recent photic history. J Clin Endocrinol Metab 89:3610-3614

78. Souman JL, Borra T, de Goijer l et al (2018) Spectral tuning of white light allows for strong reduction in melatonin suppression without changing illumination level or color temperature. J Biol Rhythms 33(4):420-431

79. Spitschan M (2019) Melanopsin contributions to non-visual and visual function. Curr Opini Behav Sci 30:67-72

80. Spitschan M, Jain S, Brainard DH et al (2014) Opponent melanopsin and S-cone signals in the human pupillary light response. Proc Natl Acad Sci USA 111:15568-15572

81. Spitschan M, Aguirre GK, Brainard DH et al (2016) Variation of outdoor illumination as a function of solar elevation and light pollution. Sci Rep 6:26756

82. Spitschan M, Bock AS, Ryan J et al (2017) The human visual cortex response to melanopsindirected stimulation is accompanied by a distinct perceptual experience. Proc Natl Acad Sci U S A 114:12291-12296

83. Spitschan M, Stefani O, Blattner P et al (2019) How to report light exposure in human chronobiology and sleep research experiments. Clocks \& Sleep 1(3):280-289

84. Stephan FK, Nunez AA (1977) Elimination of circadian rhythms in drinking, activity, sleep, and temperature by isolation of the suprachiasmatic nuclei. Behav Biol 20:1-16

85. Stothard ER, Mchill AW, Depner CM et al (2017) Circadian entrainment to the natural light-dark cycle across seasons and the weekend. Curr Biol 27:508-513

86. Terman JS, Terman M, Lo E-S et al (2001) Circadian time of morning light administration and therapeutic response in winter depression. Arch Gen Psychiatry 58:69-75
87. Terman M, Terman JS, Ross DC (1998) A controlled trial of timed bright light and negative air ionization for treatment of winter depression. Arch Gen Psychiatry 55:875-882

88. Thapan K, Arendt J, Skene DJ (2001) An action spectrum for melatonin suppression: evidence for a novel non-rod, non-cone photoreceptor system in humans. JPhysiol 535:261-267

89. Thorpy M (2017) International classification of sleep disorders. In: Chokroverty S (ed) Sleep disorders medicine: basic science, technical considerations and clinical aspects. Springer, New York, NY, pp 475-484

90. VidenovicA, KlermanEB, Wang Wetal (2017) Timed light therapy for sleep and daytime sleepiness associated with parkinson disease: a randomized clinical trial. Jama Neurol 74:411-418

91. Viola AU, James LM, Schlangen LJ et al (2008) Blue-enriched white light in the workplace improves self-reported alertness, performance and sleep quality. Scand J Work Environ Health 34(4):297-306. https://doi.org/10.5271/sjweh. 1268

92. Wams EJ, Woelders T, Marring l et al (2017) Linking light exposure and subsequent sleep: a field Polysomnography study in humans. Sleep. https:// doi.org/10.1093/sleep/zsx165

93. Webler F, Spitschan M, Foster R et al (2019) What is the "spectral diet" of humans? Curr Opini Behav Sci 30:80-86

94. Wehr TA (1991) The durations of human melatonin secretion and sleep respond to changes in daylength (photoperiod). J Clin Endocrinol Metab 73:1276-1280

95. Wehr TA, Moul DE, Barbato G et al (1993) Conservation of photoperiod-responsive mechanisms in humans. Am J Physiol Regul Integr Comp Physiol 265:R846-R857

96. Wirz-Justice A, Bader A, Frisch U et al (2011) A randomized, double-blind, placebo-controlled study of light therapy for antepartum depression. JClin Psychiatry 72:986-993

97. Wirz-Justice A, Benedetti F, Terman M (2013) Chronotherapeutics for affective disorders: a clinician's manual for light and wake therapy, 2nd edn. Karger Medical and Scientific Publishers, Basel, Switzerland

98. Wirz-Justice A, Bromundt V (2013) Lichttherapie. Schlaf 2:20-29

99. Wirz-Justice A, Graw P, Kräuchi K et al (1996) 'Natural'light treatment of seasonal affective disorder. J Affect Disord 37:109-120

100. Woelders T, Leenheers T, Gordijn MCM et al (2018) Melanopsin- and L-cone-induced pupil constriction is inhibited by $\mathrm{S}$ - and $\mathrm{M}$-cones in humans. Proc Natl Acad SciU SA 115:792-797

101. WrightHR, LackLC(2001) Effect of light wavelength on suppression and phase delay of the melatonin rhythm. Chronobiol Int 18:801-808

102. Wright KP, Mchill AW, Birks BR et al (2013) Entrainment of the human circadian clock to the natural light-dark cycle. Curr Biol 23:1554-1558

103. Wulff K, Gatti S, Wettstein JG et al (2010) Sleep and circadian rhythm disruption in psychiatric and neurodegenerative disease. Nat Rev Neurosci 11:589

104. Yetish G. et al. (2015) Natural sleep and its seasonal variations in three pre-industrial societies. Current Biology 25(21):2862-2868

105. Youngstedt SD, Elliott JA, Kripke DF (2019) Human circadian phase-response curves for exercise. JPhysiol 597:2253-2268
106. Zeitzer JM (2018) When is a proxy not a proxy? The foibles of studying non-image forming light. J Physiol 596:2029-2030

107. Zeitzer JM, Dijk D-J, Kronauer RE et al (2000) Sensitivity of the human circadian pacemaker to nocturnal light: melatonin phase resetting and suppression. JPhysiol 526:695-702

108. Zeitzer JM, Fisicaro RA, Ruby NF et al (2014) Millisecond flashes of light phase delay the human circadian clock during sleep. J Biol Rhythms 29:370-376

109. Zele AJ, Adhikari P, Feigl B et al (2018) Cone and melanopsin contributions to human brightness estimation. J Opt Soc Am A Opt Image Sci Vis 35:B19-B25

110. Zhang B-B, Yao Y-Y, Zhang H-F et al (2017) Left Habenula mediates light-preference behavior in Zebrafish via an asymmetrical visual pathway. Neuron 93:914-928.e914 